\title{
Stability Improvement of Isolated Wind-Diesel System with Optimized STATCOM Controller
}

\author{
Sasmita Behera ${ }^{1, *}$ and M. Chinmaya Prakash Sahoo ${ }^{2}$ \\ ${ }^{1,2}$ Dept. of Electrical \& Electronics Engineering, Veer Surendra Sai University of \\ Technology, Burla, 768018, India \\ 1*sasmitabehera2000m@gmail.com, ${ }^{2}$ cschinmay163@gmail.com
}

\begin{abstract}
Herein a reactive-power control scheme for an isolated wind-diesel hybrid generation with an induction generator (IG) for extraction of wind power and a synchronous generator $(S G)$ for diesel-generator $(D G)$ is presented. The reactive power consumed by $I G$ and load is supplied by the Static Synchronous Compensator (STATCOM). Terminal voltage deviation is controlled by the STATCOM and thereby balances the reactive power. To optimize the PI controller adopted in the STATCOM, Teaching Learning Based Optimization (TLBO) and its modification: opposition based TLBO (OTLBO) has been used for minimizing integral time square error (ITSE). The mathematical model of the reactive-power-flow is presented. The parameters of the algorithm are set. The performance of OTLBO and TLBO is compared with Grey Wolf Optimizer (GWO), where OTLBO excels in all respect. The transient responses of the isolated system are also revealed for 1\%, 5\% and 20\% step change in load reactive power for optimal STATCOM controller. The eigen-value analysis shows improvement in stability by the designed controllers. With the fitness function considered and rigorous optimization of the controller, the settling of the transient was possible within less than half of the time taken in earlier studies.
\end{abstract}

Keywords: $S G, W G-D G, I G, S T A T C O M, T L B O, O T L B O, G W O$

\section{Introduction}

Nowadays renewable power generation is increasing as it is eco-friendly, clean and sustainable as compared to generation from fossil fuels. But, for the irregular availability of wind and sun, they are hybridized with a diesel generator (DG) for reliable power supply to a small scale isolated system [1,2]. The DG is of synchronous type. Asynchronous generation for varying wind speed, rugged construction and other advantages [3] make induction generator (IG) a suitable and cost-effective solution for it. But, the inducing flux is maintained by reactive power consumption. With the added demand for reactive power by IG, the generation faces mismatch. Thus, generator terminal voltage is more prone to fluctuation in such case and has detrimental effect on the supply quality and stability [4]. Hence, it is an important problem to be mitigated. Some solutions have been proposed in favour of the support from fixed capacitor bank for reactive power [5]. But, such demand of IG varies with load and wind, hence the fixed capacitors are the inadequate solution [6]. Alternatively, a family of Flexible AC transmission system (FACTS) devices [7] such as Switched Capacitor, Static VAR Compensator (SVC), [8, 9] Static Synchronous Compensator (STATCOM) can supply/absorb reactive power [10-21].

Received (February 2, 2018), Review Result (May 6, 2018), Accepted (May 30, 2018)

* Corresponding Author 
For isolated applications, essentially an effective capacitive VAR controller is required for the WT-IG. Here, a STATCOM, [17] with a voltage source converter (VSC) fits and it smoothly produces inductive/capacitive reactive power with the bidirectional flow. After going through the above-referred works, it is observed that for proper control of the wattless component in an isolated system, the controller are either proportional $(\mathrm{P})$ or proportional plus integral (PI) type. If at all the controller is used, it is tuned by minimizing integral square of error (ISE) performance index on the deviation of voltage so that both positive or negative error can be reduced and thereby reducing overshoot or undershoot. But, it is noticed that the settling time of oscillations and steady-state error are high. Also, the tuning of the controller gains has been achieved by the conventional method. In [9] the PI controller gains for SVC and Automatic Voltage Regulator (AVR) have been optimized by Genetic Algorithm (GA). Optimization algorithms have imparted outstanding results with the help of computer program to attain optimal gains for controllers for stable operation in various fields of engineering. So there is scope for further improvement of STATCOM performance.

The integral time square error (ITSE) index is used in this work to optimally set controller gains as it also considers time. Hence it is effective in reducing settling time also [22]. To optimize, Teaching Learning Based Optimization (TLBO) has been used $[23,25]$. The performance of TLBO was improved by introducing opposite population modifying it to Opposition based TLBO (OTLBO) whose improved performance is also presented in this problem. The performance of TLBO is judged side by side with Grey Wolf Optimizer (GWO), a recent one [24]. The parameters of the algorithms are first set in this context. The studied result of stability and transient responses of the isolated system are also revealed for $1 \%, 5 \%$ and $20 \%$ step change in load reactive demand for optimal STATCOM controller.

The mathematical model of the isolated system is depicted in Section 2. In Section 3 the features of TLBO and its modification is discussed. Section 4 embodies the results and responses of the system bringing out significant conclusions.

\section{Mathematical Model of the System}

The system under study has a DG, IG as wind generator (WG), consumer load and STATCOM as in Figure 1. First, the system state equations are obtained. The reactive power requirement in the system is assessed from terminal voltage deviation. The STATCOM is commanded by a Proportional-Integral (PI) controller as input to eradicate the reactive power difference. Also, the excitation system of the synchronous generator responds to voltage variation and helps to mitigate it.

The load asctive demand is met by the induction generator (IG) and synchronous generator (SG) in DG. The net reactive requirement for the operation of WG and load is supplemented by the DG and STATCOM.

The reactive power balance under steady state, [6]:

$Q_{D G}+Q_{C O M}=Q_{W G}+Q_{L}$

where reactive powers in pu kVAR owe to that $Q_{D G}$, by SG in DG set; $Q_{C O M}$, by STATCOM; $Q_{L}$, demand by the load (per unit kilovolt-amperes reactive); and $Q_{W G}$, by IG in wind generator. For the small signal analysis, let the small increment in reactive power load be ${ }^{\Delta Q_{L}}$. By the action of the AVR and STATCOM, the reactive-power generation augments by an amount $\Delta Q_{D G}+\Delta Q_{C O M}$. The mismatch in this watt-less demand equals $\Delta Q_{D G}+\Delta Q_{C O M}-\Delta Q_{W G}-\Delta Q_{L}$. This will dually raise the terminal voltage:

1) by increasing the rate $(\mathrm{d} / \mathrm{dt})$ of electromagnetic-energy ( $\left.E_{E M}\right)$ in the IG; 
2) by a rise in reactive power input giving more voltage. The mathematical expression is

$\Delta Q_{D G}+\Delta Q_{C O M}-\Delta Q_{W G}-\Delta Q_{L}=d / d t\left(\Delta E_{E M}\right)+D_{V} \Delta V$

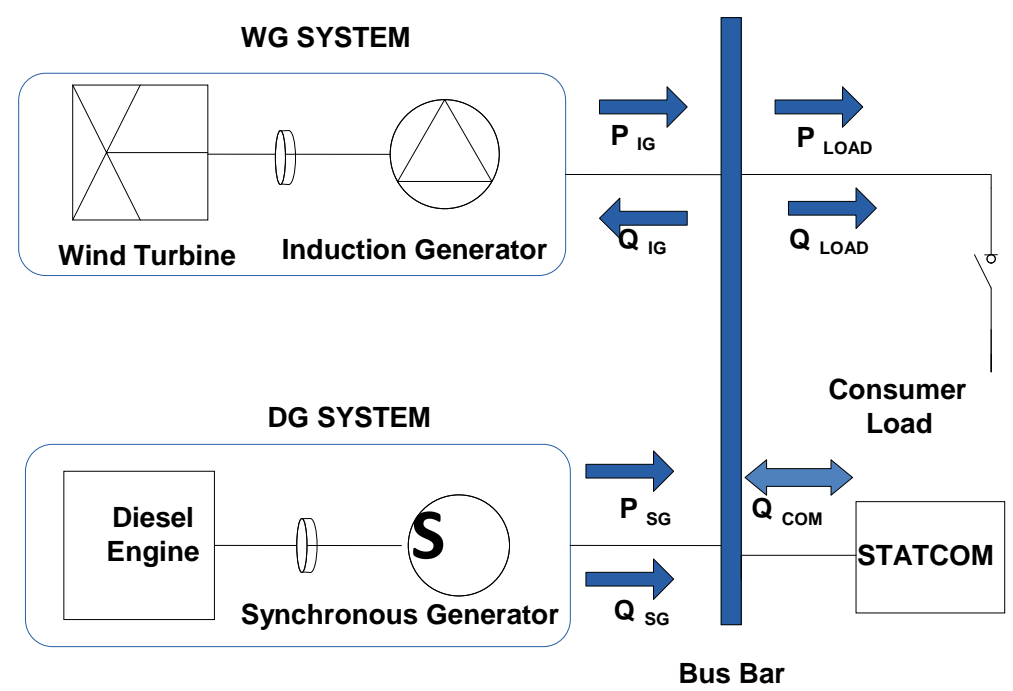

Figure 1. The Isolated Wind-Diesel Hybrid Power Scheme

The electromagnetic energy accumulated in the WG is expressed by

$E_{E M}=1 / 2 L_{M} I_{M}^{2}$

The increment $\Delta E_{E M}$ can be written as

$\Delta E_{E M}=E_{E M}-E_{E M}^{0}=2\left(E_{E M}^{0} / V^{0}\right) \Delta V$

Where $I_{M}, L_{M}$, and $X_{M}$ are the current drawn, inductance, and reactance of the IG, respectively.

Here $V^{0}$ and $E_{E M}^{0}$ quantify the terminal voltage and electromagnetic energy accumulated in the WG respectively in steady operating point.

Using (4), (2) can be written as

$$
\begin{aligned}
& \Delta Q_{D G}+\Delta Q_{C O M}-\Delta Q_{W G}-\Delta Q_{L}=2\left(E_{E M}^{0} / V^{0} Q_{R}\right) d / d t(\Delta V)+D_{V} \Delta V \\
& E_{E M}^{0} / Q_{R} \text { is given by }
\end{aligned}
$$$$
E_{E M}^{0} / Q_{R}=1 /\left(4 \Pi f K_{R}\right)=H_{R}
$$

where $H_{R}$ represents the system inertia, $\mathrm{f}$ is the frequency of emf generated and $K_{R}$ equals to system reactive-power rating divided by the rated magnetizing reactive power of WG. Substituting from (6) in (5), and taking Laplace transform, it is rewritten as

$\Delta V(s)=K_{V} /\left(1+s T_{V}\right)\left[\Delta Q_{D G}+\Delta Q_{C O M}-\Delta Q_{W G}-\Delta Q_{L}\right]$

where

$T_{V}=2 H_{R} / D_{V} V^{0}$ and $K_{V}=1 / D_{V}$. 
In Laplace transform, ${ }^{\Delta Q_{D G}(s)}$ can be written as

$\Delta Q_{D G}(s)=K_{3} \Delta E_{q}^{\prime}(s)+K_{4} \Delta V(s)$.

Where in

$K_{3}=(V \cos \delta) / X_{d}^{\prime}$ and $K_{4}=\left(E_{q}^{\prime} \cos \delta-2 V\right) / X_{d}^{\prime}$.

Also

$E_{q}^{\prime}(s)=1 /\left(1+s T_{G}\right)\left[K_{1} \Delta E_{f d}(s)+K_{2} \Delta V(s)\right]$

where

$T_{G}=X_{d}^{\prime} T_{d 0}^{\prime} / X_{d} ; K_{1}=X_{d}^{\prime} / X_{d}$ and $K_{2}=\left(X_{d}-X_{d}^{\prime}\right) \cos \delta / X_{d}$.

Here, $\Delta E_{f d}$ and $\Delta E_{q}^{\prime}$ are the small variation in the field voltage and armature in q axis under transient conditions, respectively. $T_{d 0}^{\prime}$ is the $\mathrm{d}$ axis open-circuit transient time constant. $\delta$ is the power angle. $X_{d}$ and $X_{d}^{\prime}$ are d axis reactance of synchronous generator under steady-state and transient conditions, respectively.

Similarly, for constant slip, derived from machine model [13]:

$\Delta Q_{W G}(s)=K_{5} \Delta V(s)$

Where,

$K_{5}=2 V X_{e q} /\left(R_{Y}^{2}+X_{e q}^{2}\right) ; R_{Y}=R_{p}-R_{e q}$ and $R_{p}=\left(R_{2}^{\prime} / s\right)-1$.

The STATCOM can produce or take in reactive power by proper firing angle $\alpha$ of the inverter and maintain the desired terminal voltage of the interconnection [17]. So

$\Delta Q_{\text {COM }}=f(\alpha, V)$

The linearized STATCOM model is stated as:

$\Delta Q_{C O M}=\frac{\partial Q}{\partial \alpha} \Delta \alpha+\frac{\partial Q}{\partial V} \Delta V$

$\Delta Q_{\text {СОM }}(s)=K_{7} \Delta \alpha(s)+K_{6} \Delta V(s)$

Where

$$
\Delta \alpha=\left(K_{p}+K_{i} / s\right) \Delta V
$$

Wherein, $K_{p}$ and $K_{i}$ are respective gains of the PI controller in the STATCOM controller.

The developed transfer function model is shown in Figure 2. The fitness function taken is ITSE as it gives the better reduction of overshoot and settling time.

Fitness function

$J=\int_{T}^{T s i m} \Delta V^{2} d t$

Where $T_{\text {sim }}$ is the simulation run time.

The problem of STATCOM controller optimization presented here is an offline optimization taken up by OTLBO. 


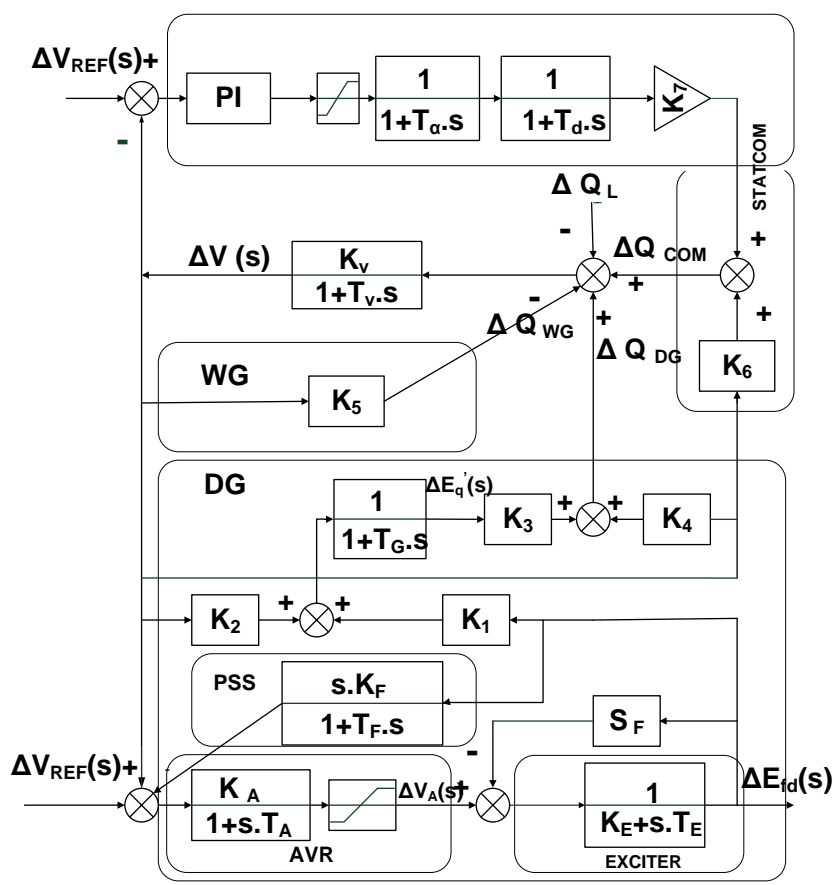

Figure 2. Transfer Function Model of the Scheme

\section{Oppositional Teaching-Learning-Based Optimization (OTLBO) Algorithm}

In a classroom, each individual learns not only from the teacher but also from the fellow learners to get the best grades. Based on this, the TLBO algorithm has two main parts of learning: (i) From the teacher (named the teacher phase) and (ii) From other students (named the learner phase). TLBO takes a population of students (i.e., learner) for whom the different subjects are the variables to optimize. The net grade of the student is analogous to the objective function. The best student as per fitness/objective function is taken as a teacher.

\section{Teaching Part}

In this part, a teacher teaches the students and improvises the average performance of the class. For a ' $\mathrm{m}$ ' dimensional problem with population size ' $\mathrm{n}$ ' number of learners $(\mathrm{k}=$ $1,2, \ldots, \mathrm{n})$. At a step, $\mathrm{i}$, of the cycle ${ }^{M_{j, i}}$ is the mean performance of the students in a specific subject ' $\mathrm{j}$ ' $(\mathrm{j}=1,2, \ldots, \mathrm{m})$. Denoting $X_{\text {total-kbes, }, i}$ as the best result or teacher taking all the subjects, due to the diversity of students, the students' results deviate from that of teacher and the mean in each subject i.e.,

Difference_mean $=r_{i}\left(X_{j . k, b e s t i}-T_{f} M_{i, j}\right)$

Where the teaching factor

$T_{f}=\operatorname{round}\left[1+r_{f}\{2-1\}\right]$

and $X_{j . k, b e s t i}$ is the best grade (teacher) in subject j. $r_{i}$ and $r_{f}$ are randomly generated in $[0,1]$. The feature $T_{f}$ need not be adjusted as a parameter but it maintains search diversity. The existing performance is improved in teacher phase as per the equation:

$X_{j . k . i}^{\prime}=X_{j . k . i}+$ Difference_mean ${ }_{j, i}$ 
If $X_{j . k . i}^{\prime}$ has a better result, then it is selected as per the fitness function evaluation. On completion of the teacher phase, the selected function values enter the learner phase. In TLBO only population size and the number of generations are tuned not $r_{i}, r_{f}$ and $T_{f}$. Thus, it is easy to implement the algorithm for a problem which reduces the time for setting control parameters.

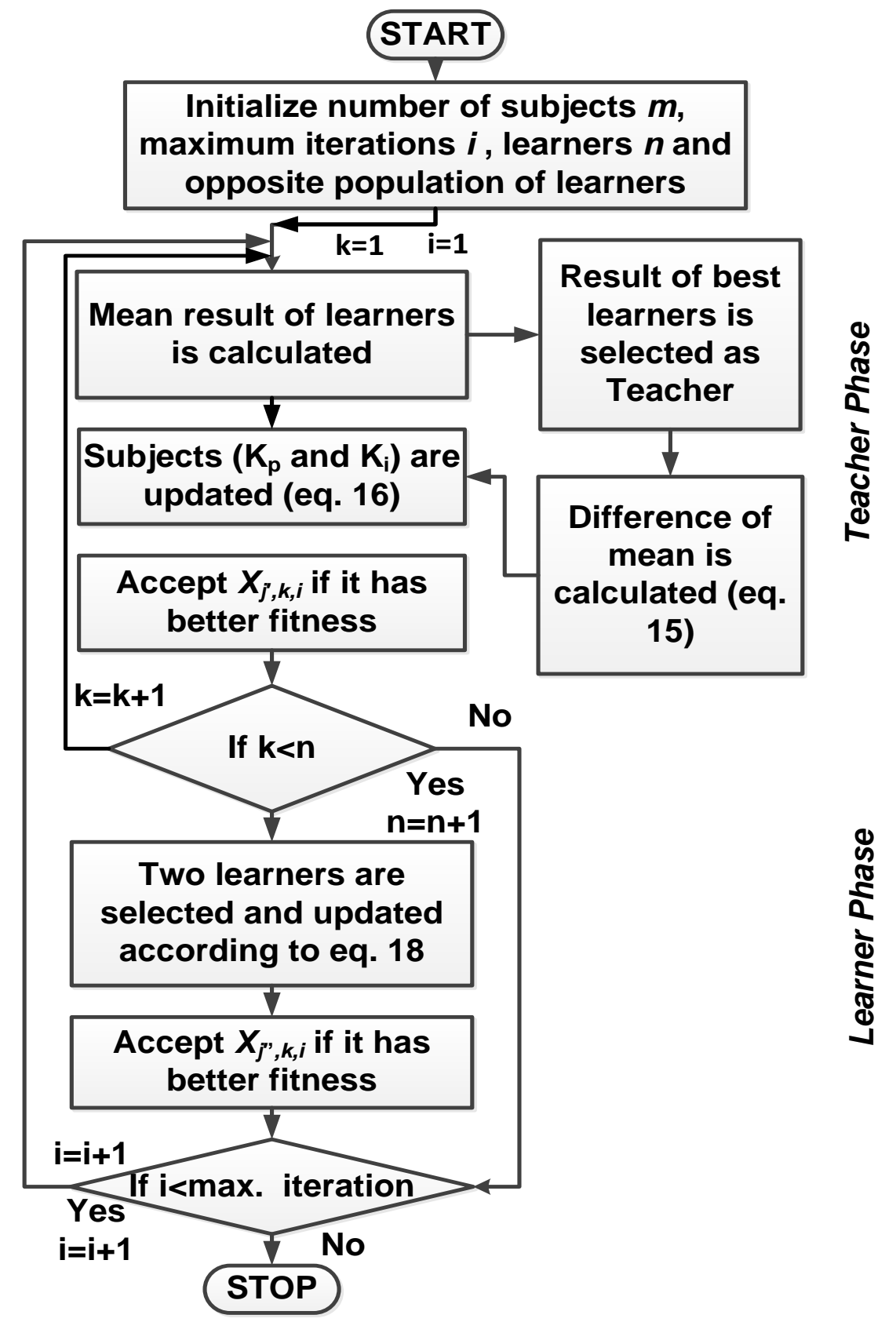

Figure 3. Flowchart for OTLBO Algorithm

Learning Part

Besides teaching, the students acquire knowledge by the cooperative discussion with classmates. An inferior learner learns from superior one who acquired more knowledge. The learning process is stated as below. After teacher phase, selecting two learners, A and $\mathrm{B}$, such that $X_{\text {total }-j, A, i}^{\prime} \neq X_{\text {total }-j, B, i}^{\prime}$ and student A updates to $X_{j . P . l}^{\prime \prime}$ as below: 


$$
\begin{aligned}
& X_{j . A . i}^{\prime \prime}=X_{j . A . i}^{\prime}+r_{i}\left(X_{j . A . i}^{\prime}-X_{j . B . i}^{\prime}\right), \text { If } X_{j . A . i}^{\prime}<X_{j . B . i}^{\prime}, \\
& X_{j . A . i}^{\prime \prime}=X_{j . A . i}^{\prime}+r_{i}\left(X_{j . B . i}^{\prime}-X_{j . A . i}^{\prime}\right), \text { If } X_{j . B . i}^{\prime}<X_{j . A . i}^{\prime}
\end{aligned}
$$

In a similar manner to teaching part $X_{j . P . i}^{\prime \prime}$ is allowed if it is a superior one.

\section{Opposition Population}

The opposition population is generated in OTLBO for better convergence result from normal class $X\left[x_{i, 1}, x_{i, 2} \ldots . x_{i, n}\right]$ with bounds $\left[l b_{j}, u b_{j},\right]$ for $\mathrm{j}=1 \ldots . \mathrm{n}$ as

$$
x_{i, j}^{O}=l b_{j}+u b_{j}-x_{i, j}
$$

In both teaching and learning part, the opposite population is evaluated and updated in a similar way as above and better solution of the total population is considered. The flow of the algorithm can be clearly understood from Figure 3.

\section{Simulation Results}

The mathematical model depicted in Section 3 is built in MATLAB Simulink with parameters in Appendix A $[8,15]$. The transients are assessed in the time domain and compared to determine $K_{p}$ and $K_{i}$.

\subsection{Optimization of $K_{p}$ and $K_{i}$}

The model is simulated for $1 \%$ step change of load and the following $K_{p}, K_{i}, \Delta \mathrm{V}$, settling time, overshoot, undershoot and the fitness function ITSE's lowest value are taken. The set of the values for $K_{p}$ and $K_{i}$ that minimize the fitness function is selected. Three optimizations namely, OTLBO, TLBO and GWO are compared here. The model is simulated in MATLAB SIMULINK 7.9 run in Intel i5 with 8 GB RAM.

First, TLBO is selected as the optimization algorithm and the parameters are set. Three sets of population size and iteration are taken. For each set of population size and iteration, the algorithm is run 20 times and best cases are shown for comparison of performance as tabulated in Table 1. It can be seen that increase in iterations increases

\begin{tabular}{|c|c|c|c|c|c|c|c|c|c|}
\hline $\begin{array}{l}\dot{0} \\
\dot{\sim} \\
\dot{n}\end{array}$ & 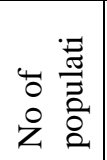 & .0̃ & $K_{p}$ & $K_{i}$ & $\Delta \mathrm{V}$ & $\mathrm{J}=\mathrm{ITSE}$ & $\begin{array}{l}\text { Settling } \\
\text { time (s) }\end{array}$ & $\begin{array}{l}\text { Over- } \\
\text { shoot }\end{array}$ & Under-shoot \\
\hline 1 & 30 & 40 & $\begin{array}{l}20.72 \\
27121 \\
28846 \\
627 \\
\end{array}$ & $\begin{array}{l}9386 . \\
08518 \\
43890 \\
54 \\
\end{array}$ & $\begin{array}{l}4.12396 \\
923418 \\
917 \\
\times 10^{-11} \\
\end{array}$ & $\begin{array}{l}2.20944 \\
350792 \\
479 \\
\times 10^{-14} \\
\end{array}$ & $\begin{array}{l}4.65135 \\
276611 \\
9749 \\
\times 10^{-11} \\
\end{array}$ & $\begin{array}{l}1.21128 \\
392529 \\
3932 \\
\times 10^{-4} \\
\end{array}$ & $\begin{array}{l}- \\
7.602689511 \\
157098 \times 10^{-4}\end{array}$ \\
\hline 2 & 30 & 50 & $\begin{array}{l}20.72 \\
27125 \\
09795 \\
823 \\
\end{array}$ & $\begin{array}{l}9386 . \\
08606 \\
81693 \\
03 \\
\end{array}$ & $\begin{array}{l}4.12396 \\
836511 \\
267 \\
\times 10^{-11} \\
\end{array}$ & $\begin{array}{l}2.20944 \\
350792 \\
481 \\
\times 10^{-14} \\
\end{array}$ & $\begin{array}{l}4.65135 \\
189101 \\
1103 \\
\times 10^{-11} \\
\end{array}$ & $\begin{array}{l}1.21128 \\
403171 \\
550 \\
\times 10^{-4} \\
\end{array}$ & $\begin{array}{l}- \\
7.602689508 \\
792526 \times 10^{-4}\end{array}$ \\
\hline 3 & 30 & 60 & $\begin{array}{l}20.72 \\
27133 \\
00350 \\
055\end{array}$ & $\begin{array}{l}9386 . \\
08544 \\
11038 \\
30\end{array}$ & $\begin{array}{l}4.12396 \\
905363 \\
152 \\
X 10^{-11}\end{array}$ & $\begin{array}{l}2.20944 \\
350792 \\
479 \\
X 10^{-14}\end{array}$ & $\begin{array}{l}4.65135 \\
262553 \\
6452 \\
X 10^{-11}\end{array}$ & $\begin{array}{l}1.21128 \\
402447 \\
8502 \\
\times 10^{-4} \\
\end{array}$ & $\begin{array}{l}- \\
7.602689504 \\
104288 \times 10^{-4}\end{array}$ \\
\hline
\end{tabular}
accuracy.

Table 1. Parameter Variation Effect of TLBO 
Table 2. Parameter Variation Effect of OTLBO

\begin{tabular}{|c|c|c|c|c|c|c|c|c|c|}
\hline$\frac{\dot{0}}{\dot{z}}$ & 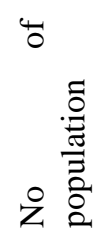 & . & $K_{p}$ & $K_{i}$ & $\Delta \mathrm{V}$ & $\mathrm{J}=\mathrm{ITSE}$ & $\begin{array}{l}\text { Settling } \\
\text { time }(\mathrm{s})\end{array}$ & $\begin{array}{l}\text { Over- } \\
\text { shoot }\end{array}$ & Under-shoot \\
\hline 1 & 30 & 40 & $\begin{array}{l}21.52 \\
95872 \\
53715 \\
7\end{array}$ & $\begin{array}{l}9754 . \\
55492 \\
89053 \\
8\end{array}$ & $\begin{array}{l}3.81767 \\
787909 \\
989 \times 10 \\
-11\end{array}$ & $\begin{array}{l}2.04172 \\
472204 \\
9410 X 1 \\
0^{-14}\end{array}$ & $\begin{array}{l}4.3059 \\
X 10^{-11}\end{array}$ & $\begin{array}{l}1.16723 \\
431744 \\
698 \\
\text { X10-4 }\end{array}$ & $\begin{array}{l}- \\
7.343777103 \\
44419 \times 10^{-4}\end{array}$ \\
\hline 2 & 30 & 50 & $\begin{array}{l}21.52 \\
95873 \\
89829 \\
5\end{array}$ & $\begin{array}{l}9754 . \\
55527 \\
70864 \\
5\end{array}$ & $\begin{array}{l}3.81767 \\
758331 \\
788 \\
X 10^{-11}\end{array}$ & $\begin{array}{l}2.04172 \\
472204 \\
9421 \\
X 10^{-14}\end{array}$ & $\begin{array}{l}4.3059 \\
X 10^{-11}\end{array}$ & $\begin{array}{l}1.16723 \\
435547 \\
645 \\
X 10^{-4}\end{array}$ & $\begin{array}{l}- \\
7.343777102 \\
70677 \times 10^{-4}\end{array}$ \\
\hline 3 & 30 & 60 & $\begin{array}{l}21.52 \\
95872 \\
53715 \\
7\end{array}$ & $\begin{array}{l}9754 . \\
55492 \\
89053 \\
8\end{array}$ & $\begin{array}{l}3.81767 \\
787909 \\
989 \\
X 10^{-11}\end{array}$ & $\begin{array}{l}2.04172 \\
472204 \\
9410 \\
X 10^{-14}\end{array}$ & $\begin{array}{l}4.3059 \\
X 10^{-11}\end{array}$ & $\begin{array}{l}1.16723 \\
431744 \\
698 \\
X 10^{-4}\end{array}$ & $\begin{array}{l}- \\
7.343777103 \\
44419 \times 10^{-4}\end{array}$ \\
\hline
\end{tabular}

From Table 1 it is observed that the least value of ITSE comes for $K_{p}$ $=20.722713300350055$ and $K_{i}=9386.085441103830$. The best results are obtained for population size 30 run for 60 iterations. From Table 2 it is observed that minimum of ITSE is the same for all the three cases of varying number of iterations for OTLBO. It indicates the consistency of the algorithm and brings up the fact that 40 runs are sufficient with OTLBO to get the convergent result, which is an improvement on TLBO. Comparing ITSE in Table 1 and Table 2, OTLBO has significantly minimized ITSE as compared to TLBO and that also reflects in the reduction of overshoot, undershoot, settling time and steady-state value of $\Delta \mathrm{V}$. For comparison, GWO is selected as this algorithm is also parameter-free [24]. In a similar manner, the performance of GWO is quantified in Table 3.

Table 3. Parameter Variation Effect of GWO

\begin{tabular}{|c|c|c|c|c|c|c|c|c|c|}
\hline $\begin{array}{l}\dot{0} \\
\dot{z} \\
\dot{n}\end{array}$ & 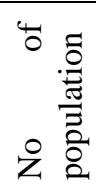 & 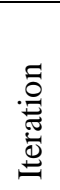 & $K_{p}$ & $K_{i}$ & $\Delta \mathrm{V}$ & ITSE & $\begin{array}{l}\text { Settling } \\
\text { time }(\mathrm{s})\end{array}$ & $\begin{array}{l}\text { Over- } \\
\text { shoot }\end{array}$ & $\begin{array}{l}\text { Under- } \\
\text { shoot }\end{array}$ \\
\hline 1 & 30 & 40 & $\begin{array}{l}20.73 \\
8529\end{array}$ & $\begin{array}{l}9427 . \\
5933\end{array}$ & $\begin{array}{l}4.083134 \\
9586255 \\
8 \times 10^{-11}\end{array}$ & $\begin{array}{l}2.2094791 \\
6022499 \\
\times 10^{-14}\end{array}$ & $\begin{array}{l}4.6057328 \\
27171594 \\
\text { X10 }\end{array}$ & $\begin{array}{l}1.2161 \\
X 10^{-4}\end{array}$ & $\begin{array}{l}-7.6026 \\
X 10^{-4}\end{array}$ \\
\hline 2 & 30 & 50 & $\begin{array}{l}20.74 \\
7339\end{array}$ & $\begin{array}{l}9395 . \\
3286\end{array}$ & $\begin{array}{l}4.116356 \\
1835003 \\
6 \times 10^{-11}\end{array}$ & $\begin{array}{l}2.2094518 \\
4707280 \\
\times 10^{-14}\end{array}$ & $\begin{array}{l}4.6427179 \\
42636307 \\
\times 10^{-11}\end{array}$ & $\begin{array}{l}1.2137 \\
X 10^{-4}\end{array}$ & $\begin{array}{l}-7.6026 \\
X 10^{-4}\end{array}$ \\
\hline 3 & 30 & 60 & $\begin{array}{l}20.72 \\
4951\end{array}$ & $\begin{array}{l}9399 . \\
7491\end{array}$ & $\begin{array}{l}4.110244 \\
6003106 \\
4 \times 10^{-11}\end{array}$ & $\begin{array}{l}2.2094474 \\
9179710 \\
\text { X10 }\end{array}$ & $\begin{array}{l}4.6360386 \\
36632027 \\
X 10^{-11}\end{array}$ & $\begin{array}{l}1.2127 \\
\mathrm{X} 10^{-4}\end{array}$ & $\begin{array}{l}-7.6027 \\
X 10^{-4}\end{array}$ \\
\hline
\end{tabular}

From the above table, it is observed that the least value of ITSE comes for $K_{p}=$ 20.724951 and $K_{i}=9399.7491$ for population size 30 run for 60 iterations. 
Overall, comparing the best ITSE values for all the three the order from best to worst is OTLBO, TLBO and GWO. The convergence of objective function i. e., cost plotted for best cases of GWO and OTLBO algorithms taken are compared in Figure 4.

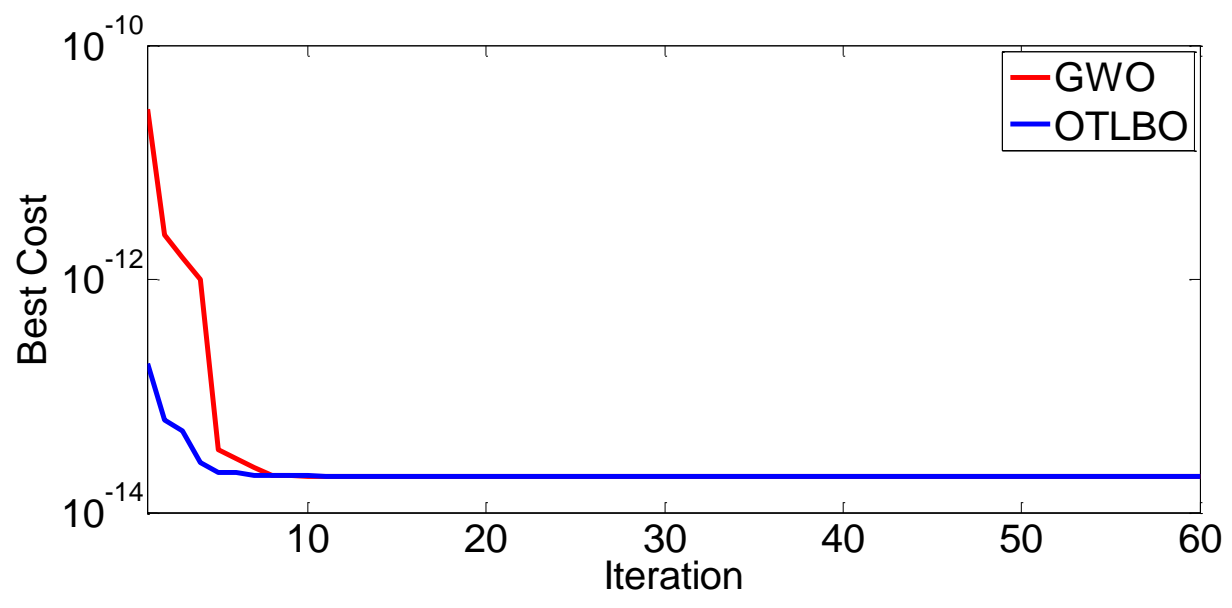

Figure 4. Convergence Plot

Here it is observed that the OTLBO converges faster and more accurately than GWO. It can also be seen that OTLBO has started with good function value and reached the best in seven iterations, TLBO has also reached the best value around seven iterations though not shown here. This gives an indication that fewer iterations of OTLBO can save time without loss of accuracy. But, the best controller gains obtained in all the three algorithms for the third row in the respective table is considered for future simulations in controlling the STATCOM for a consistent comparison.

\subsection{Comparison of Results with and Without STATCOM}

The deviations in bus voltage $\Delta \mathrm{V}$, the reactive powers: supplied by $\mathrm{SG}, \Delta \mathrm{Q}_{\mathrm{DG}}$,

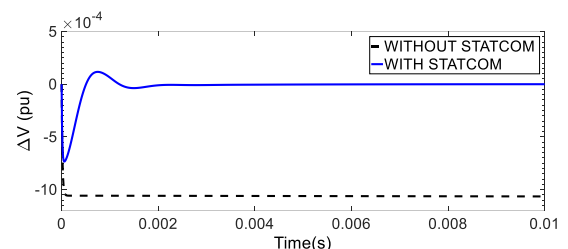

Fig. $5(\mathrm{a})$

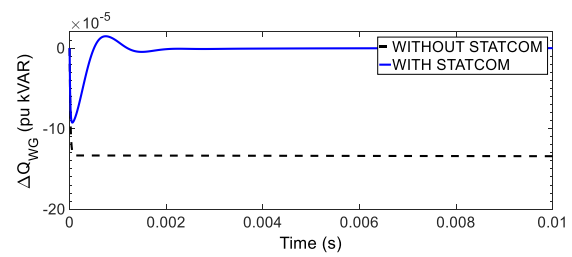

Fig. 5(c)

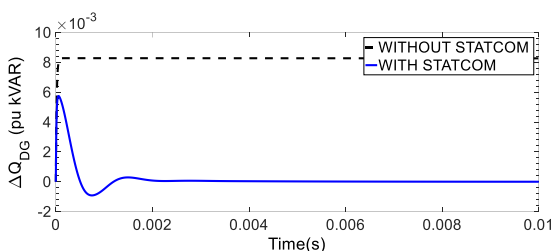

Fig. $5(b)$

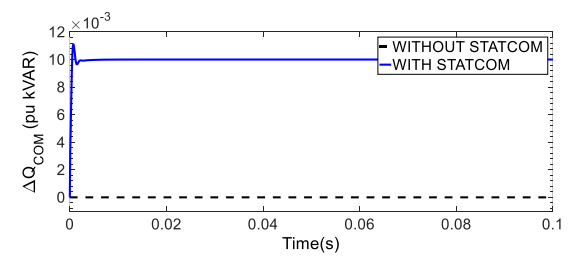

Fig. $5(d)$

Figure 5. Transient Responses of System Showing (a) $\Delta \mathbf{V}$ (b) $\Delta \mathbf{Q}_{D G}$ (c) $\Delta \mathbf{Q}_{W G}$ (d) $\Delta$ Qcom with $1 \%$ Load

consumed by IG, $\Delta \mathrm{Q}_{\mathrm{WG}}$ and generated by STATCOM, $\Delta \mathrm{Q}_{\mathrm{Com}}$ are presented in Figure 5 (a), (b), (c) and (d) respectively for 1\% load change with and without STATCOM.

It is observed that at an instant increase of load the terminal voltage reduced. This resulted in raising the supply of $\Delta \mathrm{Q}_{\mathrm{DG}}$ and $\Delta \mathrm{Q}_{\mathrm{COM}}$. The $\Delta \mathrm{Q}_{\mathrm{DG}}$ decreases as $\Delta \mathrm{V}$ reduces. 
The reactive power needed by the load eventually shifts to STATCOM when steady state is reached. In earlier works for the similar rating of system optimized using ISE criteria only the improvement in overshoot and undershoot have been reported [10-18]. But, it can be seen that the overshoot in $\Delta \mathrm{V}$ was mostly in the range of $4 \times 10^{-4}$ and it was highly oscillatory response taking too long to settle around 7 cycles [16]. When optimized with the ITSE criteria the transients settle in 5 cycles. The optimal STATCOM controller designed here accurately settles the $\Delta \mathrm{V}$ following disturbance to nearly zero compared to a case where no reactive power support is given [4]. Thus a faster control is achieved.

\subsection{Transient Responses for Various Load Conditions}

The model is run for various reactive load conditions and the respective dynamic performances are observed. The eigen-values are also found out for different controllers

Table 4. Effect on eigen-values by Controllers

\begin{tabular}{|c|c|c|c|}
\hline No STATCOM & GWO-STATCOM & TLBO-STATCOM & OTLBO-STATCOM \\
\hline$-0.0600 \times 10^{-4}$ & $-8.3867 \times 10^{-4}$ & $-8.3867 \times 10^{-4}$ & $-8.3878 \times 10^{-4}$ \\
\hline$-0.5000 \times 10^{-4}$ & $\begin{array}{l}(-0.2427+0.4342 \mathrm{i}) \\
\mathrm{X} 10^{-4}\end{array}$ & $\begin{array}{l}(-0.2427+0.4342 \mathrm{i}) \\
\mathrm{X} 10^{-4}\end{array}$ & $(-0.2421+0.4451 \mathrm{i}) \times 10^{-4}$ \\
\hline $0 \times 10^{-4}$ & $\begin{array}{l}(-0.2427-0.4342 \mathrm{i}) \\
\mathrm{X} 10^{-4}\end{array}$ & $\begin{array}{l}(-0.2427-0.4342 \mathrm{i}) \\
\mathrm{X} 10^{-4}\end{array}$ & $(-0.2421-0.4451 i) \times 10^{-4}$ \\
\hline$-5.9443 \times 10^{-4}$ & $-0.0440 \times 10^{-4}$ & $-0.0440 \times 10^{-4}$ & $-0.0440 \times 10^{-4}$ \\
\hline $\begin{array}{c}(-0.0011+ \\
0.0031 \mathrm{i}) \times 10^{-4}\end{array}$ & $\begin{array}{l}(-0.0012+0.0031 \mathrm{i}) \\
\mathrm{X} 10^{-4}\end{array}$ & $\begin{array}{l}(-0.0012+0.0031 \mathrm{i}) \\
\mathrm{X} 10^{-4}\end{array}$ & $(-0.0012+0.0031 \mathrm{i}) \times 10^{-4}$ \\
\hline $\begin{array}{l}(-0.0011-0.0031 \mathrm{i}) \\
\mathrm{X} 10^{-4}\end{array}$ & $\begin{array}{l}(-0.0012-0.0031 i) \\
\mathrm{X} 10^{-4}\end{array}$ & $\begin{array}{l}(-0.0012-0.0031 \mathrm{i}) \\
\mathrm{X} 10^{-4}\end{array}$ & $(-0.0012-0.0031 i) \times 10^{-4}$ \\
\hline $\begin{array}{l}(-0.0000+ \\
0.0000 \mathrm{i}) \times 10^{-4}\end{array}$ & $-0.0000 \times 10^{-4}$ & $-0.0000 \times 10^{-4}$ & $-0.0000 \times 10^{-4}$ \\
\hline $\begin{array}{c}(-0.0000- \\
0.0000 \mathrm{i}) \times 10^{-4}\end{array}$ & $-0.0001 \times 10^{-4}$ & $-0.0001 \times 10^{-4}$ & $-0.0001 \times 10^{-4}$ \\
\hline
\end{tabular}

and tabulated in Table 4. Significant damping has been introduced in dominant eigenvalue (shown in bold) by proper design of STATCOM controller by OTLBO and stability is improved.

It is observed from Figure 6(a)-(d), that the reactive power consumption increases with increase in load. This power is initially met by the synchronous generator. The reactive demand of $20 \%$ is finally met by the STATCOM, $\Delta \mathrm{Q}_{\mathrm{Com}}$. At first the SG meets the demand raising $\Delta \mathrm{Q}_{\mathrm{DG}}$; later on, the designed PI controller for STATCOM brings down the error in $\Delta \mathrm{V}$ and settles $\Delta \mathrm{Q}_{\mathrm{wG}}$. The settling time is more or less unaffected for the controller but the overshoot has slightly increased. However, $20 \%$ increase in reactive power demand is too high and seldom occurs; the performance sensitivity in small variation up to $5 \%$ is less. When the disturbance occurs, $\Delta \mathrm{Q}_{\mathrm{WG}}$ also increases. The transient dies out within three cycles. 


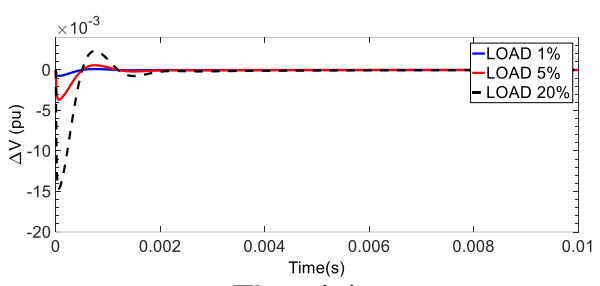

Fig.6(a)

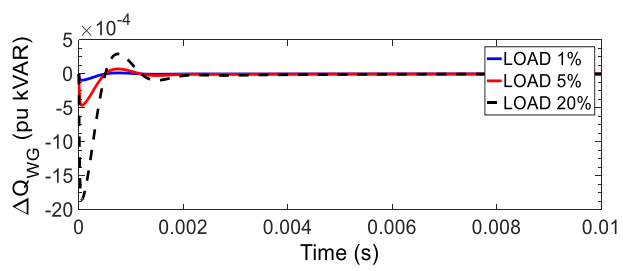

Fig.6(c)

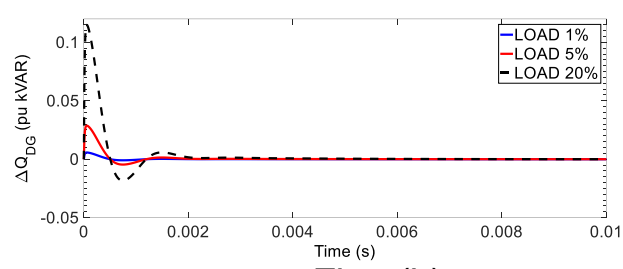

Fig.6(b)

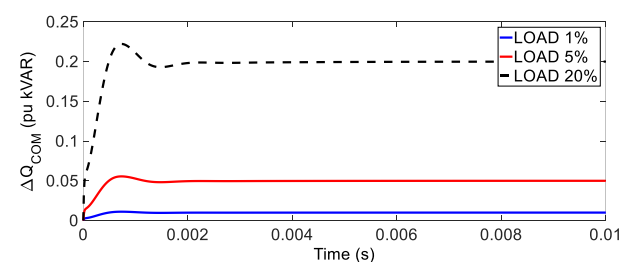

Fig.6(d)

Figure 6. Transient Responses of System Showing (a) $\Delta \mathbf{V}$ (b) $\Delta \mathbf{Q}_{D G}$ (c) $\Delta \mathbf{Q}_{w G}$ (d) $\Delta Q_{\text {com }}$ with Time for Various Load Conditions

\section{Conclusion}

The reactive power control of an isolated wind-diesel hybrid generation has been discussed. An IG generates power from wind with DG and STATCOM support in the system. The dynamics of load variation in the system is examined after optimizing the controller gains of the STATCOM using OTLBO, TLBO optimization algorithm and compared with GWO algorithm. The effect of the change in load on the dynamic performance is studied with three incremental load conditions. The least number of the control parameter of all the three algorithms reduced a significant time taken for parameter adjustment. In the process of optimization, the accuracy of OTLBO is far better as compared to the rest two. The STATCOM helps the transients caused by load disturbances to die out effectively within $0.01 \mathrm{~s}$ once the controller parameters are optimized offline. The STATCOM takes up to support the reactive power demand and steady state is attained. In future, advanced control and optimization methods can be deployed for improvement of the dynamics of isolated wind-diesel generation for larger variation and variety of load. Multiple hybrid generation systems with enhanced capacity can be studied in such aspect for benefit of isolated consumer load, instead of grid connection.

\section{APPENDIX A: $\quad$ System Parameters $[8,15]$}

\begin{tabular}{|l|l|l|l|}
\hline SYSTEM LOAD & Value & Constants & Values \\
\hline WIND CAPACITY $(\mathrm{kW})$ & 150 & $\mathrm{~K}_{\mathrm{A}}$ & 40 \\
\hline DIESEL CAPACITY $(\mathrm{kW})$ & 150 & $\mathrm{~T}_{\mathrm{A}, \mathrm{s}}$ & 0.05 \\
\hline LOAD CAPACITY $(\mathrm{kW})$ & 250 & $\mathrm{~K}_{\mathrm{f}}$ & 0.5 \\
\hline P $_{\mathrm{SG}, \mathrm{pu} \mathrm{KW}}$ & 0.4 & $\mathrm{~T}_{\mathrm{f}}, \mathrm{s}$ & 0.715 \\
\hline $\mathrm{Q}_{\mathrm{DG}}, \mathrm{pu} \mathrm{Kvar}$ & 0.2 & $\mathrm{~K}_{\mathrm{E}}$ & 1.0 \\
\hline $\mathrm{E}_{\mathrm{q}}, \mathrm{pu}$ & 1.1136 & $\mathrm{~S}_{\mathrm{F}, \mathrm{s}}$ & 0.0 \\
\hline$\delta,{ }^{\circ}$ & 21.05 & $\mathrm{~T}_{\mathrm{E}}, \mathrm{s}$ & 0.55 \\
\hline $\mathrm{E}_{\mathrm{q}}{ }^{\prime}, \mathrm{pu}$ & 0.9603 & $\mathrm{~T}_{\alpha}, \mathrm{s}$ & 0.005 \\
\hline
\end{tabular}




\begin{tabular}{|c|c|c|c|}
\hline $\mathrm{V}, \mathrm{pu}$ & 1.0 & $\mathrm{~T}_{\mathrm{d}}, \mathrm{s}$ & 0.001667 \\
\hline $\mathrm{X}_{\mathrm{d}}, \mathrm{pu}$ & 1.0 & $\mathrm{~K}_{1}$ & 0.15 \\
\hline $\mathrm{X}_{\mathrm{d}^{\prime}, \mathrm{pu}}$ & 0.15 & $\mathrm{~K}_{2}$ & 0.793232 \\
\hline $\mathrm{T}_{\mathrm{do}, \mathrm{S}}^{\prime}$ & 5.0 & $\mathrm{~K}_{3}$ & 6.22143 \\
\hline $\mathrm{P}_{\mathrm{IG}, \mathrm{pu} \mathrm{Kw}}$ & 0.6 & $\mathrm{~K}_{4}$ & -7.358895 \\
\hline $\mathrm{Q}_{\mathrm{WG}}, \mathrm{pu} \mathrm{kVAR}$ & 0.189 & $\mathrm{~K}_{5}$ & 0.126043 \\
\hline$P_{\text {in, }}$ pu kW & 0.75 & $\mathrm{~K}_{6}$ & 1.478 \\
\hline$\eta_{I G}, \%$ & 80 & $\mathrm{~K}_{7}$ & 1.0 \\
\hline$r_{1=} r_{2, p u}$ & 0.19 & $\mathrm{~K}_{\mathrm{v}}$ & 0.6667 \\
\hline $\mathrm{x}_{1}=\mathrm{x}_{2}, \mathrm{pu}$ & 0.56 & $\mathrm{~K}_{\alpha}$ & 0.446423 \\
\hline $\mathrm{s}, \%$ & -4.1 & $\mathrm{~T}_{\mathrm{v}}$ & 0.000106 \\
\hline $\mathrm{P}_{\mathrm{L}}$, pu kW & 1.0 & & \\
\hline $\mathrm{Q}_{\mathrm{L}}, \mathrm{pu} \mathrm{kVAR}$ & 0.75 & & \\
\hline pf (lagging) & 0.8 & & \\
\hline $\begin{array}{l}\mathrm{Q}_{\mathrm{COM}}=\mathrm{Q}_{\mathrm{WG}}+\mathrm{Q}_{\mathrm{L}}-\mathrm{Q}_{\mathrm{DG}}, \mathrm{pu} \\
\mathrm{kVAR}\end{array}$ & 0.739 & & \\
\hline $\mathrm{Q}_{\mathrm{c}}$,pu kVAR & 0.85 & & \\
\hline$\alpha$, radians & 2.443985 & & \\
\hline
\end{tabular}

\section{References}

[1] R. Hunter, and G. Elliot, "Wind-diesel systems: a guide to the technology and its implementation", Cambridge University Press, New York, (1994).

[2] H. Nacfaire, "Wind-diesel and wind autonomous energy systems", CRC Press, England, (1989).

[3] R. C. Bansal, T. S. Bhatti and D. P. Kothari, "Bibliography on the application of induction generators in nonconventional energy systems", IEEE Transactions on Energy Conversion, vol. 18, no. 3, (2003), pp. 433-439.

[4] A. Tah and D. Das, "Analysis and investigation on direct and cross coupling effect of small isolated and interconnected wind diesel power generating system", IET Renewable Power Generation, vol. 11, no. 2, (2016), pp. 215-227.

[5] A. K. Tandon, S. S. Murthy and G. J. Berg, "Steady state analysis of capacitor self-excited induction generators", IEEE transactions on power apparatus and systems, no. 3, (1984), pp. 612-618.

[6] R. C. Bansal, "Automatic reactive power control of autonomous hybrid power systems", (Doctoral dissertation), (2002).

[7] N. G. Hingorani, L. Gyugyi and M. El-Hawary, "Understanding FACTS: concepts and technology of flexible AC transmission systems", New York: IEEE press, vol. 2, (2000).

[8] R. C. Bansal, "Automatic reactive-power control of isolated wind-diesel hybrid power systems", IEEE Transactions on Industrial Electronics, vol. 53, no. 4, (2006), pp. 1116-1126.

[9] S. Vachirasricirikul, I. Ngamroo and S. Kaitwanidvilai, "Coordinated SVC and AVR for robust voltage control in a hybrid wind-diesel system”, Energy Conversion and Management, vol. 51, no. 12, (2010), pp. 2383-2393.

[10] B. Singh, S. S. Murthy and S. Gupta, "Analysis and design of STATCOM-based voltage regulator for self-excited induction generators", IEEE Transactions on Energy Conversion, vol. 19, no. 4, (2004), pp. 783-790.

[11] P. Sharma, N. K. Saxena and T. S. Bhatti, "Study of autonomous hybrid power system using SVC and STATCOM", International Conference on IEEE, (2009), pp. 1-5.

[12] P. Sharma, N. K. Saxena, K. S. S. Ramakrishna and T. S. Bhatti, "Reactive power compensation of isolated wind-diesel hybrid power systems with STATCOM and SVC", International Journal on Electrical Engineering and Informatics, vol. 2, no. 3, (2010), pp. 192-203.

[13] P. Sharma, "Transient stability investigations of the wind-diesel hybrid power systems", International Journal of Energy, Information, and Communications, vol. 1, no. 1, (2010), pp. 49-63. 
[14] N. K. Saxena, “Autonomous Hybrid Power System Using Statcom”, MIT International Journal of Electrical and Instrumentation Engineering, vol. 1, no. 1, (2011), pp. 49-53.

[15] P. Sharma, T. S. Bhatti and K. S. S. Ramakrishna, "Control of reactive power of autonomous winddiesel hybrid power systems", In Power Electronics, Drives and Energy Systems (PEDES) \& 2010 Power India, 2010 Joint International Conference, IEEE, (2010), pp. 1-6.

[16] P. Sharma, T. S. Bhatti and K. S. S. Ramakrishna, "Performance of Statcom in an Isolated Wind-Diesel hybrid power system", International Journal of Green Energy, vol. 8, no. 2, (2011), pp. 163-172.

[17] N. K. Saxena and A. Kumar, "Analytical Comparison of Static and Dynamic Reactive Power Compensation in Isolated Wind-Diesel System Using Dynamic Load Interaction Model", Electric Power Components and Systems, vol. 43, no. 5, (2015), pp. 508-519.

[18] P. Farhang, S. Jalilzadeh and A. Kazemi, "Modeling and simulation of a wind farm in the presence of power electronic devices for the enhancement of transient stability", Simulation, vol. 89, no. 6, (2013), pp. $735-745$.

[19] V. Vanitha and N. Devarajan, "Transient Stability Improvement of a squirrel cage induction generator in wind farm using STATCOM with Supercapacitor", Wind Engineering, vol. 36, no. 2, (2012), pp. 197218.

[20] K. N. Sam, N. Kumaresan, N. A. Gounden and R. Katyal, "Analysis and control of wind-driven standalone doubly-fed induction generator with reactive power support from stator and rotor side", Wind Engineering, vol. 39, no. 1, (2015), pp. 97-112.

[21] K. Navin Sam, N. Kumaresan, N. Ammasai Gounden and R. Katyal, "Optimal reactive power controller for wind-driven stand-alone doubly fed induction generators", Wind Engineering, vol. 41, no. 2, (2017), pp. 124-143.

[22] S. Behera, C. P. Sahoo, B. Subudhi and B. B. Pati, "Reactive power control of isolated wind-diesel hybrid power system using grey wolf optimization technique", Procedia Computer Science, vol. 92, (2016), pp. 345-354.

[23] R. V. Rao, V. J. Savsani and D. P. Vakharia, "Teaching-learning-based optimization: a novel method for constrained mechanical design optimization problems", Computer-Aided Design, vol. 43, no. 3, (2011), pp. 303-315.

[24] S. Mirjalili, S. M. Mirjalili and A. Lewis, "Grey wolf optimizer", Advances in Engineering Software, vol. 69, (2014), pp. 46-61.

[25] P. K. Roy, C. Paul and S. Sultana, "Oppositional teaching learning based optimization approach for combined heat and power dispatch", International Journal of Electrical Power \& Energy Systems, vol. 57, (2014), pp. 392-403. 
International Journal of Control and Automation

Vol. 11, No. 10 (2018) 